\title{
Cystic dystrophy of the pancreas in patient with only one previous cyst
}

\author{
E. Beleta ${ }^{1}$, M. Peghin ${ }^{2}$ and L. Guarner ${ }^{1}$ \\ ${ }^{1}$ Digestive Unit. Vall d'Hebron University Hospital. ${ }^{2}$ Department of Internal Medicine. \\ Vall d'Hebron University Hospital. Barcelona, Spain
}

\begin{abstract}
Case report: we describe the case of a 46-year-old patient with cystic dystrophy of the pancreas admitted for alcoholic pancreatitis in a state of alcohol deprivation. The patient's background includes two cases of acute pancreatitis and a computed tomography taken 18 months prior to admittance reveals a $9 \mathrm{~mm}$ cyst in the first duodenal portion. Magnetic resonance imaging and endoscopic ultrasonography were consistent with cystic dystrophy of the pancreas without stenosis, for which reason treatment with octreotide was initiated.

Discussion: it is believed to be a disease caused by obstruction of the ducts of the heterotopic pancreas and is associated with alcoholic pancreatitis. Its treatment is still under debate, but it requires pancreatectomy as a last option.

Conclusion: cystic dystrophy of the pancreas is a rare disease and an effort should be made to bring together all of the described cases to increase our understanding of the disease.
\end{abstract}

Key words: Cystic dystrophy. Duodenal cyst.

Beleta M, Peghin M, Guarner L. Cystic dystrophy of the pancreas in patient with only one previous cyst. Rev Esp Enferm Dig 2011; 103: 95-97.

\section{INTRODUCTION}

Cystic dystrophy in heterotopic pancreas is an uncommon disease. It was described for the first time by Ducle$\mathrm{rt}$ in 1970 (1). It is produced by the formation of cysts in the heterotopic pancreas in the gastro-enteric wall, main-

Received: 05-04-10.

Accepted: 15-06-10.

Correspondence: Esther Beleta. e-mail: esther_beleta@yahoo.es ly the duodenal, in the stomach and in the jejunum, with an incidence ranging from 0.5 to $14 \%$ on necroscopic examination (2). In the majority of cases, it is associated with chronic alcoholic pancreatitis (3). Most patients present clinical signs of pain and vomiting, with a thickened duodenal wall (4). Magnetic resonance imaging (MRI) or computed tomography (CT) are the tests used for the initial diagnosis, but endoscopic ultrasonography (EUS) is preferred. Its treatment depends on clinical signs and is under debate, gastro-intestinal anastomosis being recommended when there are clinical signs of obstruction (2).

\section{CASE REPORT}

A 46-year-old patient with a very severe alcohol habit, greater than $150 \mathrm{~g} / \mathrm{day}$, and a smoker of 1.5 packs/year, was admitted to emergency care after being found in a public place in convulsions.

Background includes two episodes of acute pancreatitis four and three years prior to admission, respectively, and one last admittance for acute alcoholic pancreatitis in another center 18 months before admission to our center with a CT showing a $9 \mathrm{~mm}$ cyst in the first duodenal portion.

Upon arrival to the emergency room, the patient had Glasgow 15/15 with diaphoresis and peripheral shaking; he related having decreased alcohol consumption over previous few days due to an increase in abdominal pain. $\mathrm{He}$ did not recount vomiting. Tests revealed $\mathrm{Hb} 13 \mathrm{~g} / \mathrm{dL}$, Hto $40 \%$, leukocytes 8,500 ( N 57\% ) x10E9L, platelets 202.900x10E9/L, TQ 76\%, INR 1.36 seg., glucose $79 \mathrm{mg} / \mathrm{dL}$, creatinine $0.59 \mathrm{mg} / \mathrm{dL}$, total bilirubin 1.37 $\mathrm{mg} / \mathrm{dL}, \mathrm{Na} 138 \mathrm{mmol} / \mathrm{L}, \mathrm{K} 3.6 \mathrm{mmol} / \mathrm{L}$, ASAT $281 \mathrm{UI} / \mathrm{L}$, ALAT 74 UI/L, FA 70 UI/L, GGT 541 UI/L, pancreatic alpha-amylase $222 \mathrm{UI} / \mathrm{L}$ with amylasuria $3638 \mathrm{UI} / \mathrm{L}$. Serotherapy and analgesics were started, also requiring midazolam infusion for 48 hours due to alcohol deprivation. 
A cholangio MRI (Fig. 1) was taken, revealing a focal pancreatitis of the pancreaticoduodenal groove with pseudocyst and thickened duodenal wall without producing stenosis, consistent with duodenal cystic dystrophy, and an endoscopic ultrasonography revealed heterogeneous pancreas with incipient signs of chronic pancreatitis, hyperechoic spots, lobular parenchyma, hyperechoic enhancement of the Wirsung and, as for the duodenum, thickening of the duodenal wall with intramural cystic lesions in genu and second duodenal portion. Given that the patient was asymptomatic in terms of the dystrophy, medical treatment with octreotide was initiated.

Alcohol detoxification was achieved in parallel, managing a reduction in the doses of benzodiazepines to $15 \mathrm{mg}$ of diazepam per day and initiating interdictor. The abdomen $\mathrm{CT}$ scan reveals a solid renal lesion measuring $2 \mathrm{~cm}$ in the lower right renal pole consistent with hypernephroma, for which the patient was put under outpatient observation by urological services.

\section{DISCUSSION}

Cystic dystrophy of the pancreas is a complication that is almost exclusive to the heterotopic pancreas in the periampullary region (5). It is generally found in Caucasian men in their 50s. The pathophysiology is believed to be caused by the obstruction of the ducts of the heterotopic pancreas, creating repeating acute pancreatitis and later chronic pancreatitis with duodenal thickening. Alcohol is believed to play an important role as a precipitating factor (6). For other authors, cystic dystrophy is an extension of preexisting chronic pancreatitis (7). The clinical signs may be caused by obstruction, acute pancreatitis or jaundice. Even though it can be diagnosed using CT or MRI, EUS provides a histological diagnosis as well.

As for treatment, various clinical studies have been carried out with few patients but good results $(6,8)$. Octreotide has proven to be effective mainly in patients with cystic dystrophy of the pancreas associated with chronic pancreatitis. There are also studies in which endoscopic fenestration of cysts has been carried out. Various surgical techniques have been tested with organ preservation and intestinal bypass, but due to the recurrence of clinical signs the majority of patients eventually require cephalic duodenopancreatectomy (9).

In conclusion, cystic dystrophy of the pancreas is a rare disease that requires the bringing together of cases to be able to carry out studies with a greater number of patients and be able to study the disease in depth.

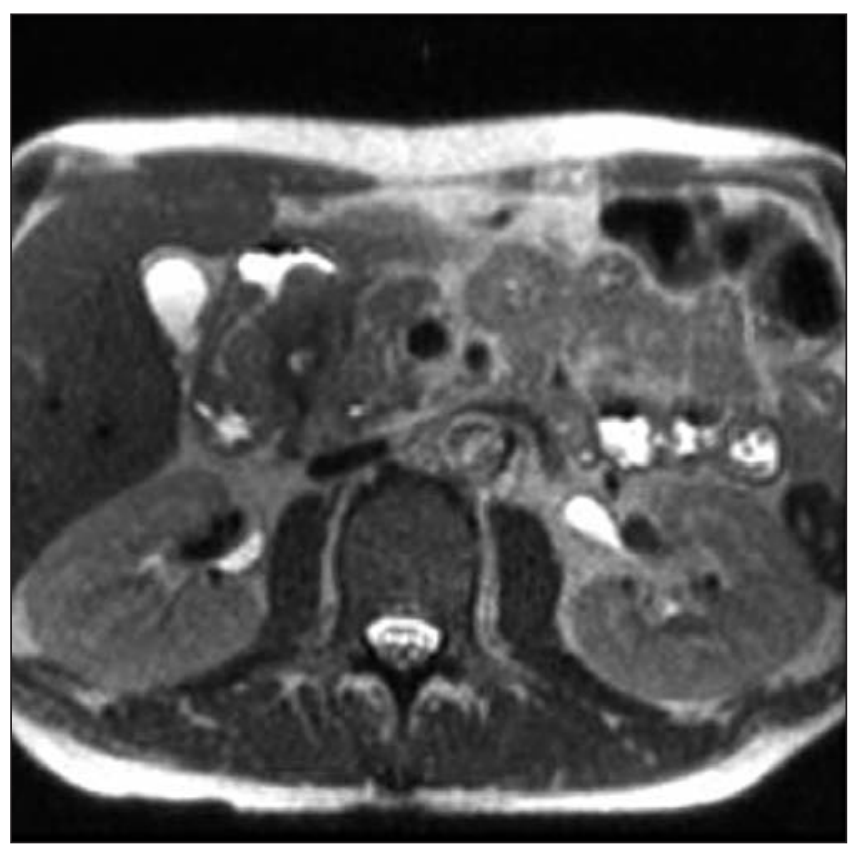

Fig. 1. Cholangiography: cystic dystrophy of the pancreas. Thickened duodenal wall with cysts adjacent to the head of the pancreas.

\section{REFERENCES}

1. Lai EC, Tompkins RK. Heterotopic pancreas. Review of a 26 year experience. Am J Surg 1986;151:697-700.

2. Galloro G, Napolitano V, Magno L, Diamantis G, Nardone G, Bruno M, Mollica C, Persico G. Diagnosis and Therapeutic Management of Cystic Dystrophy of the Duodenal Wall in Heterotopic Pancreas. A Case Report and Revision of the Literature. JOP. J Pancreas (Online) 2008; 9(6):725-732.

3. Jouannaud V, Coutarel P, Tossou H, Butel J, Vitte RL, Skinazi F, et al. Cystic dystrophy of the duodenal wall associated with chronic alcoholic pancreatitis. Clinical features, diagnostic procedures and therapeutic management in a retrospective multicenter series of $23 \mathrm{pa}-$ tients. Gastroenterol Clin Biol 2006; 30:580-6.

4. Fléjou J-F, Potet F, Molas G, Bernades P, Amouyal P, Fékété F. Cystic dystrophy of the gastric and duodenal wall developing in heterotopic pancreas: an unrecognised entity. Gut 1993;34:343-347.

5. Pessaux P, Lada P, Etienne S, Tuech JJ, Lermite E, Brehant O, Triau S, Arnaud JP. Duodenopancreatectomy for cystic dystrophy in heterotopic pancreas of the duodenal wall. Gastroenterol Clin Biol 206; 30:24-8.

6. Thomas H, Marriott P, Portmann B, Heaton N, Rela M. Cystic dystrophy in heterotopic pancreas: a rare indication for pancreaticoduodenectomy. Hepatobiliary Pancreat Dis Int 2009;8:215-217.

7. Leger L, Lemaigre G, Lenroit JP. Cysts on heterotopic pancreas of the duodenal wall. Nouv Presse Med 1974;3:2309-14.

8. Palazzo L, Chaussade S, Roseau G, Gaudric M, Larche H. Treatment of cystic dystrophy of the duodenal wall with octreotide (Sandostatine). Gastroenterology 1994;106:A313.

9. Rebours V, Lévy P, Vullierme MP, Couvelard A, O’Toole D, Aubert A, et al. Clinical and morphological features of duodenal cystic dystrophy in heterotopic pancreas. Am J Gastroenterol 2007; 102: 871-879. 